\title{
CULTURA AÇORIANA NO CONTEXTO DA CIDADE-MERCADORIA: DA INVISIBILIDADE À MERCANTILIZAÇÃO EM FLORIANÓPOLIS - SC
}

\author{
Marcia Alves Soares da Silva \\ Doutoranda em Geografia - UFPR \\ marcia.alves.geo@gmail.com
}

Recebido: 25/10/15; Aceito para publicação: 04/05/16

\begin{abstract}
RESUMO
O litoral catarinense teve uma expressiva contribuição do legado cultural açoriano, cuja colonização aconteceu em meados do século XVIII. Até hoje, essa contribuição é visível na arquitetura, culinária, tradições, lendas, histórias, modos de falar, religião, entre outras manifestações. No entanto, tal legado permaneceu por muito tempo "invisível" na história local, retomado especialmente com o avanço da urbanização e modernização das cidades, no caso desta pesquisa, em Florianópolis - SC, no intuito de reinventar uma cultura que caracterizasse o estado de Santa Catarina. Nesse contexto, muitas práticas realizadas no passado foram vistas como atrasadas, impactando o modo de vida tradicional das comunidades de origem açorianas. Esse trabalho tem por objetivo, a partir de uma discussão teóricaconceitual, compreender a relação entre a urbanização (enquanto forma-conteúdo) e a reinvenção da cultura açoriana em Florianópolis - SC levando em consideração ainda os debates sobre a cultura dentro do contexto da cidade-mercadoria, que aliada ao marketing urbano busca convencer a população local para atingir os interesses dos atores hegemônicos.
\end{abstract}

Palavras-chave: Cultura Açoriana; City-marketing; Identidade; Espaço Urbano.

\section{CULTURA DE LAS AZORES EM CONTEXTO DE LA CIUDAD-MERCANCIA: DE LA INVISIBILIDAD A MERCATILIZACIÓN EN FLORIANÓPOLIS - SC}

\begin{abstract}
RESUMEN
La costa de Santa Catarina tuvo una contribución significativa de la herencia cultural de las Azores, cuya colonización ocurrió en la mitad del siglo XVIII. Hasta la fecha, esta contribución es visible en la arquitectura, gastronomía, tradiciones, leyendas, historias, formas de hablar, la religión, entre otros eventos. Sin embargo, este legado a largo seguía siendo "invisible" en la historia local, tomada en especial con el avance de la urbanización y la modernización de las ciudades, en el caso de esta investigación, en Florianópolis - SC con el fin de reinventar una cultura que caracterizan el estado de Santa Catarina. En este contexto, se observaron muchas prácticas llevadas a cabo en el pasado como retrasados, lo que afecta la forma tradicional de vida de las comunidades de origen de las Azores. Este trabajo tiene como objetivo, a partir de una discusión teórica y conceptual, la comprensión de la relación entre la urbanización (como una forma-contenido) y la reinvención de la cultura de las Azores, en Florianópolis - SC, teniendo en cuenta también el debate sobre la cultura en el contexto ciudades-mercancías, que junto con el marketing urbano busca convencer a la población local para lograr los intereses de los actores hegemónicos.
\end{abstract}

Palabras-clave: Cultura de las Azores; City-marketing; Identidad; Espacio Urbano.

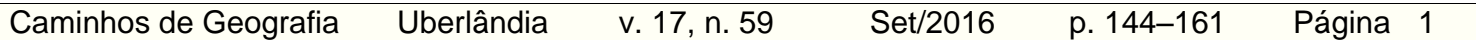




\section{INTRODUÇÃO}

O legado cultural açoriano permaneceu por muito tempo "invisível” na história de Santa Catarina, especialmente com a presença de outros imigrantes europeus, como alemães e italianos. O resgate/visibilidade da cultura açoriana no Estado é relativamente recente, com forte influência das transformações e dinâmicas urbanas, notadamente o turismo e a expansão imobiliária. $\mathrm{O}$ crescimento destes setores, atrelado especialmente ao avanço do processo de urbanização e modernização de Florianópolis - SC, local desta pesquisa, tem sido essencial na consolidação do que chamamos de cidade-mercadoria (city-marketing).

Na capital catarinense, a transformação da cidade em mercadoria diz respeito não só as suas amenidades (paisagens naturais), mas também a cultura açoriana, que entra nos circuitos de consumo, com a apropriação de muitos elementos culturais pelo mercado turístico e por vezes a invenção para o consumo. A apropriação da cultura açoriana acontece a partir da culinária (restaurantes típicos), festas (Festa do Divino, Terno-de-Reis, Boi-de-Mamão), arquitetura (preservada em alguns locais e reinventada em outros), além da figura típica do "manezinho da Ilha”.

Nesse contexto, é notável que os projetos urbanos são construídos numa lógica hegemônica de consumo do lugar. As culturas ditas tradicionais, no caso da cultura açoriana, também entram nos circuitos de mercantilização, impulsionando a consolidação de cidadesmercadorias. Em Florianópolis - SC, essas intencionalidades de mercantilização (especialmente o turismo) na produção do espaço urbano, incorporam determinadas condições históricas, formas e práticas socioculturais, na ideia de valorização do passado. Contudo, tal valorização busca atender as exigências de interesses hegemônicos, usando o discurso de desenvolvimento e progresso da sociedade para legitimar suas ações.

Os interesses desses atores são visíveis no marketing da cidade e que tem sido essencial para - que chamamos de "venda da cidade" ou cidade-mercadoria. Apoiada numa ideia de paisagens naturais e ótima qualidade de vida, Florianópolis - SC é projetada como a "Beverly Hills" brasileira, onde os anseios da camadas mais altas de renda são prontamente atendidos em detrimento das camadas mais pobres, excluídas e visivelmente indesejadas.

Nesse sentido, esse trabalho irá discutir o processo de urbanização e modernização em Florianópolis - SC, dentro de um projeto de cidade-mercadoria (city-marketing), onde o turismo e a especulação imobiliária tiveram importante papel no avanço destas questões na capital catarinense. Além disso, iremos articular tais transformações com a questão da cultura açoriana, considerada como a cultura tradicional local. O legado cultural açoriano comumente tem entrado no rol de consumo local, legitimando o projeto de cidade-mercadoria e por vezes desconsiderando os anseios e interesses dos moradores locais. Por conseguinte, o estudo sobre a preservação da cultura açoriana neste espaço mostra-se relevante porque contribui para a valorização da memória e da cultura de Florianópolis - SC e dos descendentes açorianos.

Em suma, o trabalho busca discutir como a atual produção do espaço urbano, tendo como principais atores o Estado, o capital turístico e imobiliário, transforma rapidamente o espaço, desconsiderando os interesses dos cidadãos e o direito à cidade. A escolha por trabalhar com Florianópolis - SC se dá pela maneira que a cidade vem sendo projetada pelos atores hegemônicos, em que a venda de sua cultura, com traços açorianos marcantes, faz parte dos projetos homogêneos de transformação das cidades. As pessoas acabam por perder suas referências identitárias, em que transformam-se a cultura, a história, a memória, as vivências, o cotidiano, por vezes desconsiderando as particularidades locais.

Para tanto, será apresentado, a partir de uma discussão teórica-conceitual, algumas questões relevantes para a compreensão do processo de urbanização e a influência no resgate da cultura açoriana de Florianópolis - SC. No primeiro momento, apresentaremos o debate sobre a produção do espaço urbano a partir da lógica da cidade-mercadoria e de que maneira as questões culturais são relevantes para pensarmos o urbano. Na segunda parte da discussão, debateremos a urbanização turística, especialmente porque se apropria dos contextos locais para exercer suas ações. Nessa discussão, a cultura açoriana e a sua apropriação dentro da lógica da cidade-mercadoria e da urbanização turística será brevemente apresentada, sendo

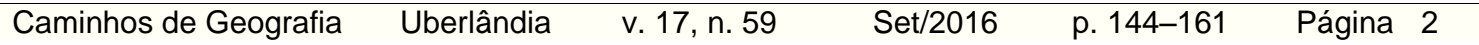


aprofundada no terceiro momento desse trabalho, contextualizando o resgate/reinvenção da cultura açoriana, especialmente em Florianópolis - SC.

Este trabalho é parte da Dissertação de Mestrado em Geografia defendida em 2014 no Programa de Pós-Graduação em Geografia da UFF, em que foram realizadas entrevistas com os moradores mais antigos de Ribeirão da llha e Pântano do Sul, duas comunidades chamadas tradicionais, localizadas no sul de Florianópolis - SC, onde a cultura açoriana estaria mais preservada. As entrevistas consistiram em algumas indagações relacionadas às mudanças em seus espaços de vivência, nas manifestações culturais e no modo de vida nos últimos anos, especialmente em decorrência das transformações evidenciadas com o processo de urbanização e o avanço do turismo. Contudo, as entrevistas não serão apresentadas neste trabalho, onde nosso objetivo é realizar uma discussão teórica-conceitual sobre a questão, relacionando os atuais projetos de urbanização da cidade, com as transformações no modo de vida das pessoas, principalmente relacionadas aos aspectos culturais e identitários.

\section{CULTURA E PRODUÇÃO DO ESPAÇO URBANO NO CONTEXTO DE CIDADE- MERCADORIA}

Os açorianos chegaram no litoral de Santa Catarina em meados do século XVIII e tiveram importante contribuição social, cultural, política e econômica, onde seu legado ainda se mostra presente em várias partes do Estado. Na capital catarinense, o rápido e intenso processo de urbanização, especialmente a partir de 1950, bem como a atividade turística, teve impacto na (re)construção da cultura açoriana pelos descendentes açorianos, já que com a chegada do processo de modernização da cidade muitas práticas tradicionais realizadas no passado foram vistas como atrasadas.

Nesse processo de modernização, a cidade aparece apenas como palco e o espaço urbano produzido tende a ser percebido apenas em suas formas, não exaltando que a produção e reprodução no espaço urbano também diz respeito as relações interpessoais, logo, relações que envolvem cultura e identidade. Por conseguinte, o espaço urbano também é fruto de uma dimensão cultural, seja por sua monumentalidade, mas também pelo seu modo de vida. Porém, o que temos são homens e relações coisificadas, em que suas obras e produtos the são subtraídos, além da ausência de comunicação e que dilui os contatos entre os sujeitos. Percebemos a perda das referências, já que o tempo urbano é o que normatiza a vida na cidade (CARLOS, 2009).

Incorporada à acumulação capitalista, que impõe uma nova lógica espacial às sociedades e torna complexa a relação entre as diferentes escalas, a cultura é transformada em mercadoria e as formas simbólicas são constantemente redefinidas, tanto materialmente quanto imaterialmente. $O$ atual processo de urbanização do mundo é generalizado, com a imposição de um novo modo de apropriação do espaço da cidade, em que tal apropriação situa-se entre a ordem próxima (indivíduos e suas relações em grupo) e ordem distante (ordem da sociedade regida pelos poderes hegemônicos) (OLIVEIRA, 2000; CARLOS, 2007; LEFEBVRE, 2001).

A forjada identificação dos indivíduos com os projetos urbanos da cidade-mercadoria acontece principalmente no plano cultural. Sobre isso, Sanchéz (2001, p. 35) acredita que "há um complexo intercâmbio entre a transformação material e o simbolismo cultural, entre a reestruturação de lugares e a construção de identidades. Desse modo, a cultura é o meio que relaciona a textura da paisagem ao texto social".

O modo de vida urbano comumente desconsidera as particularidades locais, já que normatiza a vida. Contudo, esse modo de vida está imbricado por diferentes manifestações culturais, necessárias como referências aos indivíduos e relevantes para a própria construção da identidade, tanto individual quanto coletiva. Acontece um descompasso entre o tempo da sociedade capitalista industrial e o tempo do indivíduo, da família ou do cotidiano, culminando num estranhamento espacial advindos da intensificação do processo de urbanização $\mathrm{Em}$ consequência, têm-se a desvinculação das atuais gerações com as gerações passadas, a sensação de perda dos referenciais e das raízes, enfraquecendo os laços e o sentimento de pertencimento em detrimento do "progresso", "desenvolvimento" e modernização das cidades (MONASTIRSKY, 2009).

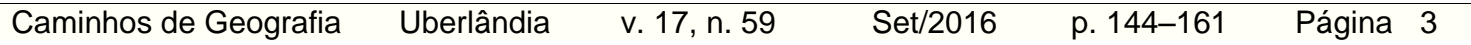


Nesse viés, a cidade tem sido idealizada como uma empresa, perdendo seu caráter de polis:

De um lado a city, impondo-se à cidade como espaço e objeto e sujeito de negócios; de outro lado, a polis, afirmando a possibilidade de uma cidade como espaço do encontro e confronto entre cidadãos. Ali onde a mercantilização do espaço público está sendo contestada, ali onde os citadinos investidos de cidadania politizam o quotidiano e quotidianizam a política, através de um permanente processo de reconstrução e reapropriação dos espaços públicos, estão despontando os primeiros elementos de uma alternativa que, por não estar ainda modelada e consolidada, nem por isso é menos promissora (VAINER, 2000, p. 101).

De acordo com Sanchéz (2003; 2001), percebe-se que o espaço urbano não é apenas um mero cenário das relações sociais, mas também uma instância para a dominação econômica ou ideológica, no qual o espaço do valor de troca impõe-se sobre o espaço do valor de uso, isto é, os modos de apropriação são cada vez mais determinados pelos mercados. O acesso ao espaço acontece pela mediação do mercado, que impõe mudanças profundas nos modos de uso e consumo, ao legitimar processos hegemônicos globais e a imposição de uma pensamento único, sendo as singularidades políticas, culturais, urbanísticas da cidade vendidas de modo semelhante. Os meios de comunicação e informação estão articulados aos interesses dominantes e são instrumentos-chave na produção da subjetividade coletiva, a partir da criação de símbolos e signos. São essas ações que constroem e legitimam as cidadesmercadoria.

Para a autora, a imagem da cidade enfatiza a importância da diversidade cultural e das diferenças étnicas, no entanto, a ideia de recuperação e preservação dessa diversidade é compreendida como recurso mercadológico, pois o patrimônio cultural e as tradições são transformadas em mercadorias. Promove-se o consumo da cidade a partir de representações manipuladas que obedecem a determinadas visões, tendo a mídia como meio de comunicação/informação na difusão e afirmação desse consumo exacerbado e a cultura como parte decisiva no mundo dos negócios.

Esses elementos, enquanto realidade prática, são ameaçados pelas integrações e desintegrações da vida cotidiana pelo empobrecimento das relações sociais (como as de vizinhança), enfraquecimento do comércio local, esvaziamento das ruas pelos moradores, substituídos pelo fluxo de automóveis. A vida cotidiana implode através do conflito entre a imposição de novos modelos culturais e comportamentais, invadidos pelo mundo mercadoria, estabelecida no plano do mundial, e as especificidades da vida no lugar apoiada em antigas relações de sociabilidade. $\mathrm{O}$ empobrecimento da vida acontece à medida que as relações entre as pessoas são substituídas por relações profissionais ou institucionais. Quando o espaço é transformado em valor de troca (cidade como negócio), ignora-se o conteúdo da prática socioespacial da cidade, sendo este processo, que se realiza como norma, invade o espaço privado, sem, no entanto, recriar identidades ou "pertencimentos" (CARLOS, 2005; 2007).

Assim, vai ganhando significado o espaço imediato da vida das relações cotidianas mais finas - as relações de vizinhança, o ato de ir às compras, o ato de caminhar, a ação que marca o encontro com os conhecidos, permite os jogos, as brincadeiras, dando sentido ao ato de habitar. Trata-se de lugares que o homem habita dentro da cidade e que dizem respeito a seu cotidiano e a seu modo de vida: lugares por onde se locomove, onde trabalha, flana, o espaço da casa e dos circuitos de compras, dos passeios, isto é, formas através das quais o homem se apropria de seu mundo imediato que vai ganhando o significado dado pelo uso e suas possibilidades. Trata-se portanto, de um espaço palpável - nesta condição específica é a extensão exterior, ou seja, o que é exterior a nós, no meio do qual nos deslocamos e agimos. Enfim, uma prática vivida e reconhecida em pequenos atos corriqueiros e, aparentemente, sem sentido, vulgares, mas que criam laços profundos de identidade entre habitante - habitante, e habitante - lugar. Deste modo não estamos nos referindo aos espaços infinitos, mas a espaços 
banais e reais como a rua, a praça, o bairro, espaços do vivido, que se revelam como os espaços-tempos da vida (CARLOS, 2007, p. 44).

Por conseguinte, a cidade torna-se palco do espetáculo, o que dificulta um olhar mais sensível sobre a realidade, ao obscurecer e eliminar o cotidiano e sua construção, as práticas culturais, a apropriação dos espaços públicos. Nessa lógica, o espaço é produzido de forma homogênea, sendo na vida cotidiana que se criam as formas, a dinâmica da vida e o seu conteúdo (CARLOS, 2009).

Tal debate mostra a pertinência da compreensão da dimensão cultural no espaço urbano, suas múltiplas manifestações e sentidos para as pessoas, já que é necessária para a construção da identidade. Compreende-se identidade não só como identificação, mas como pertencimento e enraizamento por um determinado lugar, que se modificado, também modificará a construção e a relação identitária. É emergente traduzir a vida urbana em sua realidade prático-sensível, já que a cidade também é espaço do simbólico, que desperta sentimentos, emoções e a sensibilidade das pessoas.

Em Florianópolis - SC, esses laços e a vida cotidiana por muito tempo foram marcados pelo ar tranquilo, bucólico e pacato. A capital catarinense praticamente desde a sua ocupação açoriana até meados do século XX era rural e baseada na pesca, cuja vida nos bairros possuía profundos laços com o mar, com os engenhos, com o bater dos bilros, com as cantigas de ratoeiras, com as relações de compadrio. Algumas práticas culturais açorianas, como o Ternode-Reis, Farra do Boi ou outras festas, com o tempo perderam seus espaços de manifestações, principalmente com a inserção de moradores de outras localidades, que não conhecem tais práticas e portanto não se misturam com a vizinhança, além da morte dos antigos moradores, cujas famílias não se interessam e não mantêm as tradições. Sobre isso, atualmente em locais como Pântano do Sul e Ribeirão da llha, no sul de Florianópolis - SC, muitas das relações de vizinhança se restringem aos antigos moradores, especialmente os idosos.

A preservação do modo de vida tradicional açoriano em Florianópolis - SC é um desafio frente ao contexto atual, pois construiu-se uma cidade-mercadoria, que aliado ao marketing urbano busca convencer a população local para atingir os desejos dos atores hegemônicos. Cria-se um simulacro, uma cidade acessível para poucos, descaracterizando o lugar e fragilizando o sentimento de pertencimento dos moradores locais.

\section{A URBANIZAÇÃO TURÍSTICA NA LÓGICA DE PRODUÇÃO DO ESPAÇO URBANO}

$\mathrm{Na}$ produção do espaço urbano em Florianópolis - SC, o turismo e a especulação imobiliária possuem importante influência em determinadas ações na cidade. Dentre essas ações, é relevante destacar os problemas ambientais decorrentes de algumas políticas urbanas, em que muitas áreas de preservação ambiental são prejudicadas. Há também as desapropriações em determinadas áreas, especialmente próximas às praias, no intuito de expandir resorts e balneários e possibilitar o avanço do turismo. No entanto, é importante destacar que muitas das decisões tomadas não condizem com os anseios e necessidades da população local, sendo recorrentes os conflitos entre práticas culturais tradicionais e determinadas leis vigentes.

$\mathrm{Na}$ urbanização contemporânea, especialmente em cidades turísticas como Florianópolis - SC, percebemos a articulação entre novas e velhas paisagens, usos, formas e funções. Tal movimento impulsiona a relação do lugar com o mundo, interferindo ainda na identidade do lugar, que é constantemente recriada, produzindo um espaço social híbrido, dando lugar a uma nova organização socioespacial. Nesse viés, tal movimento, entre velho e o novo, é acelerado pela urbanização turística, dando visibilidade a novos sujeitos sociais, invisibilizando e marginalizando outros, redesenhando as formas de apropriação do espaço urbano, substituindo antigos usos e elegendo novas paisagens a serem valorizadas para o lazer. "A criação destrutiva da urbanização turística desafia a todo instante a sobrevivência de antigas paisagens e a resistência do lugar" (LUCHIARI, 1998, p. 18).

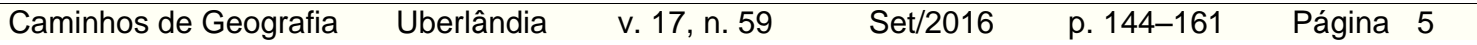


Luchiari (1998) faz uma crítica ao afirmar que há a valorização mais da técnica de reprodução do que a própria autenticidade, no qual o turismo pode reproduzir a natureza, a cultura e autenticidade de práticas sociais, mas o que dá sentido ao consumo destes simulacros é a subjetividade do indivíduo e dos grupos sociais que passam a valorizar a própria reprodução.

O turismo acentua a produção de lugares de consumo e o consumo dos lugares. A organização territorial dos lugares turísticos não responde somente à lógica do lugar, do meio, e da população local, mas é a reprodução de atributos valorizados nos centros urbanos emissores, sintetizando, na materialidade das cidades que se expandem, as novas representações sociais imprimidas ao uso do território (LUCHIARI, 1998).

\begin{abstract}
Mas não pode ser tomado apenas do ponto de vista negativo, como um desarticulador voraz de antigas formas e funções sociais que, num processo linear, destrói o velho substituindo-o pelo novo. A mediação entre o global e o local empreendida pelo turismo possibilita tomarmos o lugar e o mundo em sua unidade. Permite também trazermos à luz novas formas de sociabilidade, articuladas em função do processo contemporâneo de revalorização das paisagens para o lazer. Este movimento ao invés de contrapor o tradicional ao moderno, o lugar ao mundo, o natural ao artificial, impulsiona a restruturação das relações do lugar com o mundo e a formação de organizações socioespaciais cada vez mais híbridas, cujas formas e lógicas antigas associadas às novas originam uma nova composição. (LUCHIARI, 1998, p. 8-9)
\end{abstract}

As cidades turísticas representam uma nova forma de urbanização, voltada para o consumo de bens, serviços e paisagens, com a redefinição da vida econômica em função do turismo, no intuito de atrair através das paisagens (LUCHIARI, 1998). Temos assim, as singularidades locais e a venda do patrimônio cultural de acordo com a economia política das cidades e a lógica da economia global. Tal característica mostra a articulação interesses globais e locais.

Para a autora, o que ocorre é a valorização da diferenciação dos lugares como um atrativo para o capital, com o ressurgimento de antigas práticas, não importante mais sua função social, já que o turismo constantemente o reinventa. Não importa mais a vocação natural, já que esta pode ser artificializada e reinventada. Na corrida para obter um importante papel no processo de globalização, são os mandos e desmandos da ordem externa, que desarticulam culturas tradicionais, como é o caso da maioria das comunidades litorâneas do país.

Quando discutimos sobre as mudanças nas práticas culturais e na construção da identidade, levamos em consideração a própria mudança no modo de vida no espaço urbano, pois consideramos o urbano além das suas formas, mas como uma prática social. O debate então diz respeito não só a cultura como construção para o ser, mas também de como ela vêm sendo apropriada e vendida pelo turismo e pelo capital imobiliário, sendo muitas vezes forjados elementos culturais (figuras 1 e 2), no intuito de projetar as cidades para o mercado turístico, havendo uma apropriação e por vezes invenção das tradições locais. 
Figura 1 - Distrito de Ribeirão da llha, Florianópolis - SC. A arquitetura de influência lusa é visível na paisagem local, onde as casas até hoje são habitadas por antigos moradores.

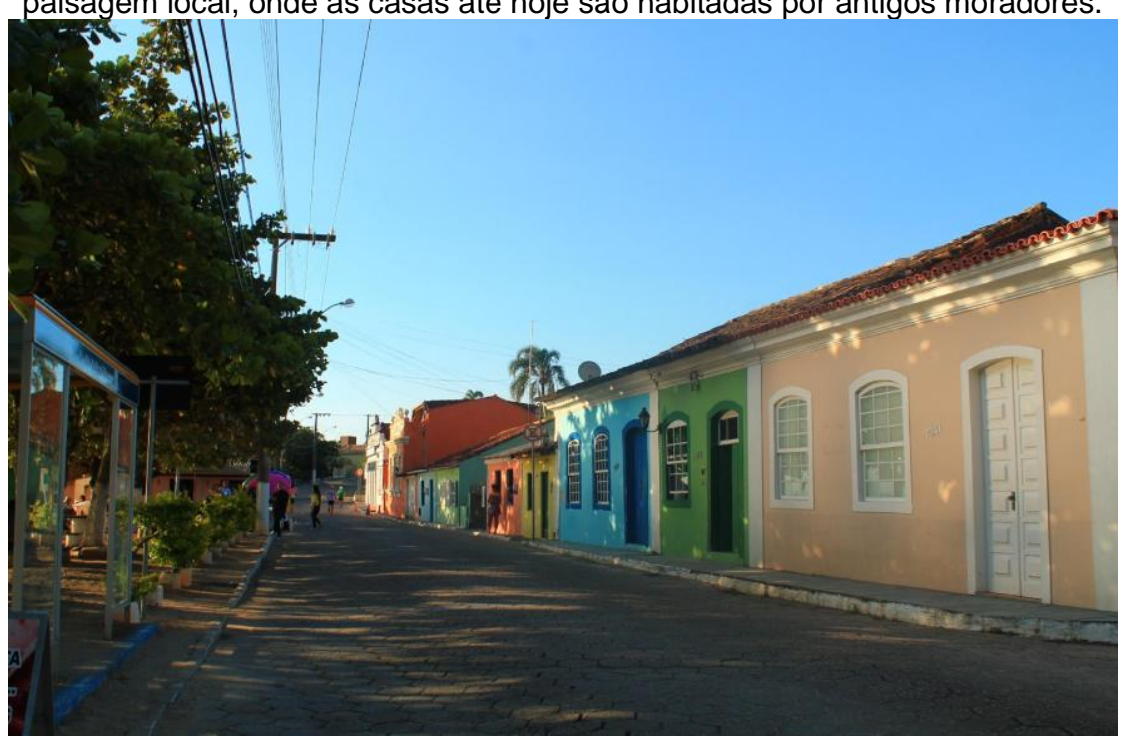

Fonte: SILVA, Marcia Alves Soares da Silva (2013).

Figura 2 - "Invenção" pelo marketing imobiliário de casas típicas açorianas em Ribeirão da Ilha -

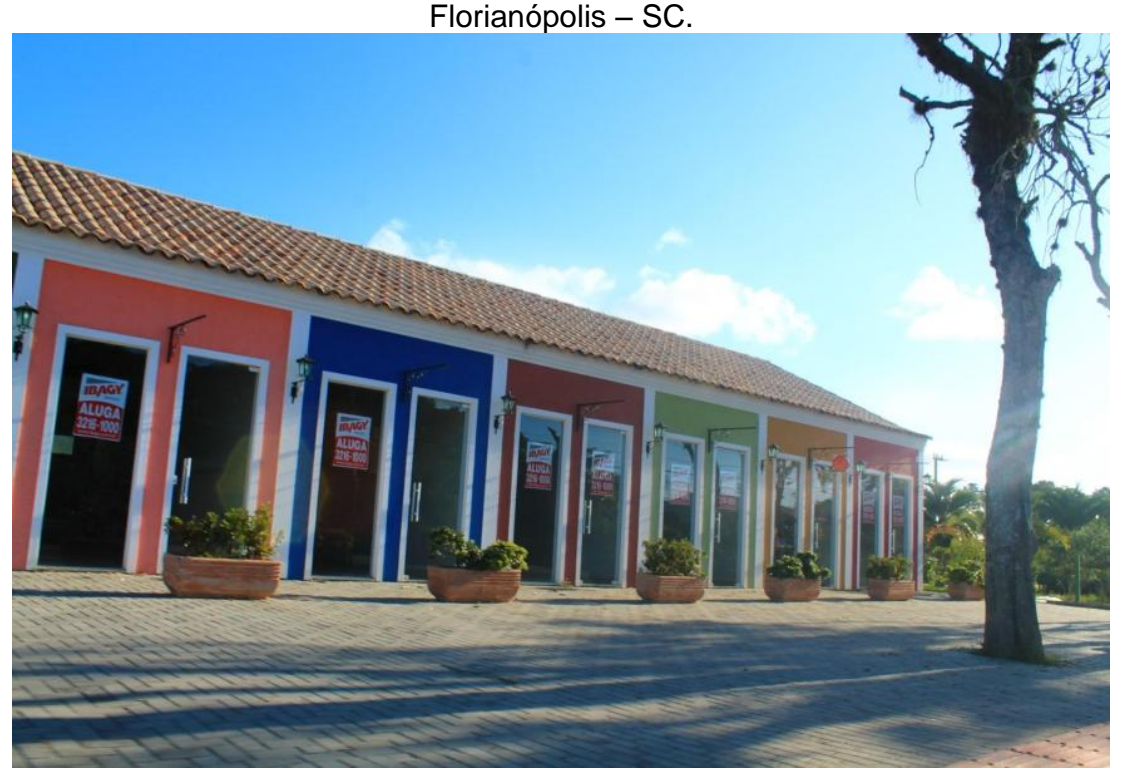

Fonte: SILVA, Marcia Alves Soares da (2012).

Com a atividade turística, as populações locais reinventam seu cotidiano e, nessa reinvenção, corre-se o risco de a lógica turística se sobrepor às tradições locais e à identidade dos lugares, pelo surgimento de novos valores, novas referências e novas expectativas.

Os espaços instrumentalizados pela lógica do capitalismo, com a função de multiplicar a produção e o consumo, em regra, convertem o espaço social e a cultura em mercadorias, modificam as paisagens e acabam por expulsar a memória (NÓR, 2010, p. 143).

Com a transformação da economia e da sociedade, Campos (2009) acredita que o turismo entra em cena a passa a ser um elemento central nos novos direcionamentos econômicos, sendo a questão cultural um atrativo para a capital catarinense, que viu no resgate dos

\begin{tabular}{|c|c|c|}
\hline Caminhos de Geografia & Uberlândia & p. $144-161$ \\
\hline
\end{tabular}


Ressalta-se ainda a importância das formas simbólicas na produção da cidade. Conforme Corrêa (2003) é por meio de determinadas formas simbólicas que a cidade expressa a cultura e realiza seu papel de transformação cultural, que acontece ao longo da História, relacionada à forma, função e significado dessas formas.

\begin{abstract}
As formas simbólicas tornam-se formas simbólicas espaciais quando diretamente relacionadas ao espaço, constituindo-se em fixos e fluxos, isto é, localizações e itinerários. [...] As relações entre formas simbólicas espaciais e política são também dotadas de nítida temporalidade. Refletem a natureza e a intensidade das transformações econômicas, políticas e sociais de cada período da História, mas também o sentido que os diversos tipos de representação material têm para a sociedade nos diversos períodos (CORRÊA, s/d, p. 3).
\end{abstract}

Nesse sentido, destaca-se a importância da preservação cultural, tanto no sentido coletivo quanto para a identidade do indivíduo. A cultura açoriana, embora tenha permanecido "apagada" do imaginário catarinense, manteve manifestações que até hoje encontram-se imbricadas no cotidiano dos moradores locais.

\begin{abstract}
Ao registrar o elenco das manifestações culturais transplantadas dos Açores para o litoral catarinense e que ainda são vivenciadas no cotidiano de nosso povo, conscientes desta história comum, defende-se a valorização dessa rede de manifestações culturais que exprimem toda a nossa Identidade. Manifestações que são legitimadoras de uma memória histórica-cultural a ser reverenciada e preservada (NUNES, 2002, p. 77).
\end{abstract}

A presença dos açorianos na então Nossa Senhora do Desterro (atual Florianópolis) foi relevante em diversas aspectos, especialmente do ponto de vista cultural. O legado açoriano por muito tempo manteve-se discreto na história local, especialmente após a chegada de colonos alemães e italianos, que de certa maneira "invisibilizaram" o chamado "praiano indolente" ou "manezinho da llha". A importância do legado cultural açoriano e o orgulho dos descendentes de suas raízes é relativamente recente no contexto catarinense, iniciando-se a partir da década de 1950, com destaque para a década de 1990.

Essa revalorização e redescoberta da cultura açoriana possui grande relação com o boom imobiliário e turístico em Florianópolis, especialmente a partir da década de 1960, com a migração de pessoas de outras capitais brasileiras devido ao avanço da urbanização e modernização da capital catarinense, aliada à construção de importantes instituições públicas, como a Universidade Federal de Santa Catarina (UFSC). A modernização da cidade e a invasão dos "de fora" transformaram a realidade de Florianópolis - SC, impulsionando os intelectuais a buscarem na história a importância do legado açoriano para a cultura local, numa necessidade de (re)construção identitária que pudesse caracterizar o Estado de Santa Catarina.

As feições culturais na capital catarinense foram se modificando com a introdução da urbanização. Quando as estradas, os turistas, o progresso e a urbanização chegam às comunidades litorâneas, o resultado é a transformação de seu modo de vida tradicional, mudanças nas atividades econômicas e transformações socioculturais (LAGO, 1996).

As primeiras transformações acontecerem no centro da capital, com a derrubada de antigos casarões, a verticalização do centro, construção de aterros e a instalação de importantes órgãos públicos, ao mesmo tempo em que há o crescimento das favelas com a desapropriação de antigos moradores. A mobilidade urbana se transforma, com aumento do fluxo de veículos, onde tiveram que invadir áreas de manguezais e areais, de preservação permanente, para a expansão de avenidas, ruas e pontes, modificando a paisagem natural. Houve ainda a

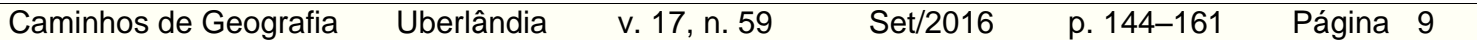


economicamente decadente, cujos hábitos e costumes de outras sociedades influem ou interagem. Nesse sentido é que se percebe a mercantilização da cultura, que é vendida como qualquer produto.

A dificuldade em manter esses valores originais tornou-se verdadeiro desafio diante da expansão do turismo balneário na região, e do avanço das mídias, que introduziam novos padrões de comportamento e apelos mercadológicos, colocando em risco de desaparecimento os tradicionais (CLETISON, 2011, p. $51)$.

De acordo com Lacerda (2003), a partir dos anos de 1980, com a modernização tardia, a explosão urbana, turística e imigratória, bem como a maior visibilização dos antigos modos de vida nas pequenas localidades praianas, colocou-se em debate os riscos reais do desaparecimento das tradições culturais locais. No entanto, o autor acredita que o vetor homogeneizante da globalização cultural e a modernização urbana do litoral catarinense, acabarão por fortalecer as condições para uma reação contra o impacto da modernização tardia e pela valorização das identidades culturais locais.

A dificuldade de preservação da cultura açoriana, além da influência do turismo e da mídia, também acontece pelos projetos de urbanização intensos em Florianópolis - SC, impulsionados pelos empreendimentos imobiliários e modernização urbana. Alguns benefícios foram possibilitados pelo planejamento urbano e pelo turismo, como saneamento, asfalto, serviços médicos, transporte. Contudo, por vezes descaracteriza o lugar, forjando elementos culturais para a venda da cidade. Atualmente, a principal fonte de arrecadação de Florianópolis - SC é através do turismo, sendo relevante pensar que nem sempre o resgate das culturas locais propiciado pelo turismo tem como intuito a preservação em si, mas a preservação para a venda, ou seja, transformando a cultura em mercadoria e vendendo a cidade.

O poder hegemônico responsável por essas transformações no espaço urbano, não leva em consideração que as mudanças do lugar de vivência modificam as relações entre as pessoas, bem como seus sentimentos, memórias, experiências com o lugar. Vale salientar que a cultura açoriana sempre teve uma grande relação com o mar e a terra, os primeiros alvos do turismo e da especulação imobiliária.

Em Florianópolis - SC, toda a lógica da colonização açoriana, responsável pela ocupação e desenvolvimento da llha, modificou-se primeiramente pela especulação da terra e fragmentação da pequena propriedade rural que passa a ter valor de troca em um mercado imobiliário crescente. Com o desenvolvimento da atividade turística, o espaço urbano passa a sofrer maior valorização e especulação, estimulando a abertura de lotes, (re)valorização de áreas, expansão da malha urbana e construção de grandes empreendimentos comerciais e residenciais (FIRMINO e CHAGAS, 2009).

Deste modo, a análise urbana de Florianópolis, pode ser compreendida como um todo, por sua troca de funcionalidade: antes uma cidade que precisava manter sua estrutura administrativa enquanto capital de um estado e que possuía em segundo plano ao turismo, grandes investimentos em capitais mercantis e empresas de tecnologia inseridas em um espaço urbano limitado pela questão ambiental, que era base para seu turismo sazonal, hoje investe em um projeto de urbanização e criação de um mercado imobiliário não mais sazonal, mas que aproveita a tendência de grupos consumidores e de alto poder aquisitivo dos grandes centros (FIRMINO e CHAGAS, 2009, p. 12).

Para Santos (2012), a implantação de infraestrutura e regulação urbanística por parte do Estado oferece rentáveis condições ao capital imobiliário, este que possui a hegemonia na dinâmica de estruturação do espaço urbano de Florianópolis - SC. Na capital catarinense, o intenso processo de produção imobiliária, transformou rapidamente a paisagem, a estrutura

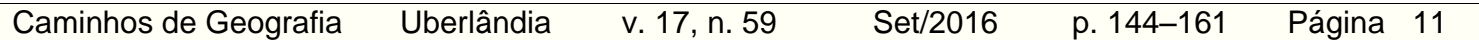


urbana e a dinâmica socioeconômica da Cidade. Resultado disso é a crise urbana: mobilidade, violência, moradia insalubres, segregação socioespacial, problemas ambientais, desequilíbrio na distribuição de serviços e equipamentos coletivos públicos.

O autor traça uma cronologia sobre as transformações urbanas da capital, a partir de 1960. Nesta época, há uma incisiva ação do Estado na dinamização de ocupação da capital, seja no que diz respeito a regulação, quanto a estrutura física, com profundas mudanças na paisagem. E criada uma nova ponte, que dinamizaria o deslocamento urbano, além da construção de várias vias de ligação, na intenção de interligar e articular antigos núcleos de ocupação, muitos deles transformados posteriormente em balneários.

Nos anos de 1980 há a consolidação do turismo, elemento-chave na expansão urbana. Ao mesmo tempo, inicia-se uma ampla campanha midiática, com o intuito de mostrar e vender o slogan de "cidade-paraíso". Essa época foi de uma urbanização intensa, tanto na área central da cidade, quanto nas regiões mais periféricas, de norte a sul da llha, impulsionadas pelo boom imobiliário, que atraia não só turistas brasileiros, mas também estrangeiros, principalmente latino-americanos.

A natureza, infraestrutura e qualidade de vida urbana são vendidos pelo marketing turístico. A partir de investimentos imobiliários privados, são construídos empreendimentos de alto padrão próximos à elementos da paisagem que são facilmente vendidos, como praias, lagoas ou balneários, especialmente a partir da fragmentação de terras comunais. Os moradores mais antigos venderam ou foram desapropriados de suas terras, antes usadas para plantio (valor de uso), que foram inseridas no mercado imobiliário, ganhando valor especulativo (valor de troca) (SANTOS, 2012).

Assim, o espaço construído na capital é a concretização de uma ideologia comandada pelo capital turístico-imobiliário, que visa a construção da cidade como mercadoria, atendendo aos interesses das empresas hegemônicas, em detrimento do bem-estar coletivo. Tal processo de urbanização segue a lógica do corporativismo e do marketing urbano, com a criação hegemônica de uma imagem de cidade que convença a população local e também investidores externos. Esse processo violento de urbanização na lógica capitalista, além de territorializar antigos bairros, também se sobrepõem aos antigos espaços de pequena produção mercantil açoriana. Muitos desses loteamentos não são legítimos, ocupam planícies litorâneas e centrais, além de manguezais e encostas, sendo que há ocupações de espaços públicos feitos pelas classes mais favorecidas. Além disso, pescadores atraídos pela oferta de ganhos com a terra, abandonam seus espaços de sobrevivência e desarticulam-se enquanto comunidade (POZZO e VIDAL, 2011; PIMENTA, 2005; NETO et al. 2003).

De acordo com Machado (2000) a urbanização de Florianópolis (ver tabela 1) não difere do que vem acontecendo na urbanização das cidades litorâneas brasileiras, impulsionando novas territorialidades e produção e consumo de paisagens. Além disso, a "face" provinciana que até recentemente prevalecia como imagem de Florianópolis está ganhando rápidas transformações, a partir de vários processos de produção espacial em curso, que desencadeiam discutíveis configurações urbanas e que dão dimensões do caráter local/regional na contemporaneidade.

Tabela 1- Dados do crescimento populacional e do grau de urbanização em Florianópolis.

\begin{tabular}{c|c|c|c}
\hline Periodo & População Total & População Urbana & Grau de Urbanização (\%) \\
\hline $1959^{\circ}$ & 97.827 & 79.870 & $81,64 \%$ \\
\hline 1970 & 138.337 & 121.028 & $87,49 \%$ \\
\hline 1980 & 187.871 & 161.773 & $86,11 \%$ \\
\hline $1991^{\circ}$ & 254.941 & 239.566 & $93,97 \%$ \\
\hline 2000 & 339.063 & 332.185 & $97,96 \%$ \\
\hline 2010 & 421.203 & 405.243 & $96,21 \%$ \\
\hline
\end{tabular}

Fonte: MACHADO (2013) baseado nos censos demográficos do IBGE.

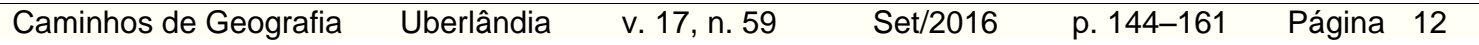


paisagística. A praia, por exemplo, transforma-se em mercadoria, não importando o espaço coletivo que se está criando, mas somente o acesso a esse bem comercializável (MONTEIRO, 2005; PIMENTA, 2005; VIKTOR, 2010).

Nesse sentido, para Lago (1996) e Dias (2009), quando as estradas, os turistas, o progresso e a urbanização chegam às comunidades litorâneas de Florianópolis - SC, o resultado é a transformação de seu modo de vida tradicional, a partir de mudanças nas atividades econômicas e transformações socioculturais. As transformações urbanas a partir dessas migrações acontece tanto no sentido concreto, com a intensificação do processo de urbanização, construção de grandes empreendimentos imobiliários para fins comerciais, residenciais e turísticos, mas também simbólicos, com a desapropriação, segregações e exclusões, afetando a preservação de elementos da cultura local.

\begin{abstract}
Com relação à cultura tradicional das populações que habitam originariamente as regiões onde se desenvolve o turismo, a complexidade do problema se avoluma. A questão envolve outros aspectos, extravasando o da simples preservação de um recurso não renovável, no interesse da continuidade da própria atividade econômica. Dizer que os usos, hábitos, costumes, rituais, artefatos, valores culturais, enfim, dever ser preservados como recursos turísticos, é argumento que só pode ser elaborado por interlocutores com visão apenas economicista e desenvolvimentista dos processos sociais. O problema transcende 0 fato econômico e tem dimensões éticas, filosóficas, sociais, psíquicas, jurídicas, etc. O direito à sobrevivência cultural é objeto nuclear e formador da própria antropologia. É tão fundamental como o direito à vida, à sobrevivência individual e das espécies. É estranho que ele precise ser afirmado, demonstrado, ou possa ser questionado (LAGO, 1996, p. 65-66).
\end{abstract}

Para Fantin (2000), são essas múltiplas experiências urbanas - de desenraizamento, de apropriação, de perda - que produzem também diferentes percepções da cidade, nutrindo e acirrando o conflito entre os "autênticos" ilhéus e os chamados "invasores". Claramente a modernização da cidade não só afetou a paisagem, mas especialmente o modo de vida dos antigos moradores, obrigados a entrarem neste novo circuito. A ideia é que a cultura da ilha está "morrendo".

A cidade deve ser percebida também pelas suas normas, códigos, regras, ou seja, identificar sua dimensão cultural, a dimensão do viver, da cotidianidade. Devemos pensar a cidade além de sua estrutura física, mas acima de tudo, a ação de seus atores, pensando uma cidadefruição, onde "A beleza da cidade é para ser vivida, curtida, preservada e não simplesmente negociada. O que se deseja é que prevaleça o valor de uso e não o valor de troca [...]" (FANTIN, 2000, p. 72).

Em suma, percebemos que as antigas relações sociais agora são mediadas pelo consumo e pelo acesso à propriedade privada, negando uma forma de vida social espontânea, pois com a privatização do espaço público, temos também a privatização da existência. Nega-se a espontaneidade da vida cotidiana, que está imbricada por uma importante construção social, cultural e identitária.

\title{
CONSIDERAÇÕES FINAIS
}

Vivenciamos o lugar de consumo e o consumo do lugar, pois hoje o valor de troca prevalece a tal ponto sobre o uso e o valor de uso que quase suprime este último. Os promotores imobiliários criam espaços de consumo, de felicidade, propagadas pela publicidade e propiciando ainda mais a venda do espaço, especialmente devido as qualidades estéticas, um importante fator na manutenção da ideia de venda da cidade (LEFEBVRE, 2001).

Nessa ótica, a valorização do que é tradicional, como as festas, a culinária, religiosidades, crenças e mitos, o artesanato, é uma forma de garantir a identidade do povo e da cidade. A

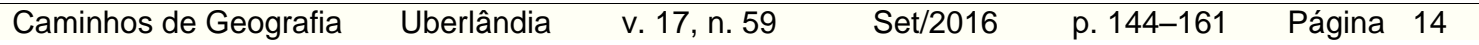


manutenção da tradição, oferece na prática, um sentido de continuidade. Por isso a necessidade de estudos que visibilizem os atores sociais como no caso dos descendentes açorianos em Florianópolis, buscando a preservação de suas raízes culturais, a defesa do lugar, bem como sua memória e identidade coletiva na tentativa de resguardar suas singularidades.

Pensamos ainda que a capital catarinense é laboratório de espetacularização da cidade, onde os projetos urbanos buscam atender as demandas do capital e não as necessidades dos moradores locais. Tais necessidades também englobam as questões culturais, dentro da discussão proposta de direito à cidade. Ressalta-se ainda o caráter privado da vida coletiva, especialmente através da generalização de um discurso, neste caso, um discurso identitário.

Buscamos refletir a importância do legado cultural açoriano não na ótica do consumo da cultura e do lugar, mas como importante elemento na construção da identidade, memória e lembranças do ser, ou seja, a discussão dentro do espaço urbano permite perceber que o direito à cidade inclui a questão da preservação e do patrimônio como instância constitutiva. É relevante pensar ainda que a cidade também é memória coletiva das pessoas, já que a memória, além dos fatos, também está ligada aos lugares. A transformação da cidade afeta a construção da memória e por vezes, a permanência de determinadas manifestações culturais.

Assim, temos o empresariamento da esfera simbólica, com imagens permanentemente construídas e destruídas, especialmente com a intervenção do capital privado no planejamento da cidade, bem como a apropriação privada de símbolos acumulados que foram criados ao longo da história dos lugares. A cidade funciona como atração para receber investimento e possibilitar seu "desenvolvimento". Os administradores da cidade são estimulados a vender a cultura local e o patrimônio histórico, permitindo ainda mais a fragmentação da cidade, onde algumas áreas são mais privilegiadas que outras, em termos de investimento e possível retorno a partir do lucro.

Se pensarmos a cultura açoriana, em seu sentido "tradicional", é notável a subordinação da vida cotidiana às imposições da economia globalizada. Alteram-se hábitos, costumes, formas tradicionais de uso do espaço urbano, onde temos por um lado, especialmente nos distritos pesquisados do sul da Ilha, uma movimentação turística na alta temporada e uma possível "preservação" do modo de vida tradicional, mas por outro, esta preservação acontece quando pode gerar algum lucro. Assim, temos a entrega da cultura e de um modo de vida, aos ditames do mercado globalizado.

A construção da identidade acontece no cotidiano. Contudo, com a negação do cotidiano, as relações coisificadas, a ausência de comunicação, as relações fragmentadas e diluição dos contatos e perda das referências, fica mais complexa a construção identitária e o sentimento de pertencimento. A vida, cada vez mais normatizada, coisifica os sentimentos e a relação com o outro, por isso torna-se importante o resgate das emoções, sentimentos, vivências, pensando a cidade para além das formas, já que o modo de vida urbano também diz respeito à questão cultural.

\section{REFERÊNCIAS BIBLIOGRÁFICAS}

ABREU, M. Sobre a memória das cidades. In: CARLOS, A.F.A. et al (Org.). A produção do espaço: agentes e processos, escalas e desafios. São Paulo: Contexto, 2011, p. 19-39.

CABRAL, O.R. Os açorianos. In: Anais Primeiro Congresso de História Catarinense. Florianópolis: Imprensa Oficial, 1950, p. 509-608.

CAMPOS, N.J. de. Açorianos do litoral catarinense. Da invisibilidade à mercantilização da cultura. Arquipélago. História, 2ª série, XIII, p. 177-201, 2009.

CARLOS, A.F.A. O espaço urbano: novos escritos sobre a cidade. São Paulo: FFLCH, 2007.

A cidade. 8 ed. São Paulo: Contexto, 2009.

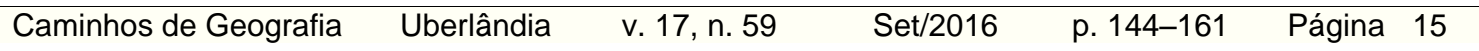


CLETISON, J. Arquipélago dos Açores e Litoral Catarinense. Século XVIII a XXI. Revista Educação em Linha. Ano V, n. 16, p. 49-51.

CORRÊA, R.L. O Urbano e a Cultura. S/d. Cd Cultura.

CORRÊA, R.L.; ROSENDAHL, Z. (Org) Introdução à Geografia Cultural. Rio de Janeiro: Bertrand Brasil, 2003.

DIAS, R.D. Que invasão é essa? Leituras sobre conflitos socioculturais em Florianópolis (1970-2000). Dissertação (Mestrado em História) - Curitiba: UFPR. 2009.

FANTIN, M. Cidade dividida. Florianópolis: Cidade Futura, 2000.

FIRMINO, L.C.; CHAGAS, L. As "novas faces" do turismo em Florianópolis/SC: uma abordagem geográfica. Anais do XII Encuentro de Geógrafos de América Latina. Uruguai, 2009.

LACERDA, E. O atlântico açoriano. Uma antropologia dos contextos globais e locais da açorianidade. Tese (Doutorado em Antropologia Social) - Florianópolis: UFSC, 2003.

LAGO, M.C. de S. Modos de vida e identidade. Sujeitos no processo de urbanização da Ilha de Santa Catarina. Florianópolis: Ed. UFSC, 1996.

LEFEBVRE, H. A vida cotidiana no mundo moderno. Ática: São Paulo, 1991.

. O direito à cidade. São Paulo: Centauro, 2001.

LUCHIARI, M.T.D.P. Urbanização turística: um novo nexo entre o lugar e o mundo. Asociación Canaria de Antropologia. n. 4. 1998.

MACHADO, E.V. Florianópolis: um lugar em tempo de globalização. Tese (Doutorado em Geografia Humana) - São Paulo: USP, 2000.

Pelas ruas, na Cidade e no Urbano: aspectos de base Luso-açoriana da Contemporaneidade de Florianópolis, SC - Brasil. Congresso Internacional "As cidades na história". Portugal, 2012.

MONASTIRSKY, L.B. Espaço urbano: memória social e patrimônio cultural. Revista Terr@ Plural. v. 3, n. 2, p. 323-334, jul/dez 2009.

MONTEIRO, C.A. Florianópolis: o direito e o avesso. In: PIMENTA, M. (org.). Florianópolis: do outro lado do espelho. Florianópolis: UFSC, 2005.

NETO, C.S.A. et al. Reflexões sobre a especulação imobiliária e os impactos sócio-ambientais em Florianópolis, SC, Brasil. Revista Katálysis. Florianópolis. v. 6. n. 2. p. 153-162, jul/dez 2003.

NÓR, S. Paisagem e lugar como referências culturais. Ribeirão da Ilha - Florianópolis. Tese (Doutorado em Geografia) - Florianópolis: USFC, 2010.

NUNES, L.P. da S. Sobrevivências culturais açorianas: a identidade da llha de Santa Catarina. In: PEREIRA, N.V. et al. A Ilha de Santa Catarina: espaço, tempo e gente. Florianópolis: Instituto Histórico e Geográfico de Santa Catarina, 2002.

OLIVEIRA, M.P. de. Geografia, globalização e cidadania. Terra Livre, n. 15, p. 155- 164, 2000.

PIMENTA, M.C.A. Florianópolis como espaço do público. In: PIMENTA, M. (org.). Florianópolis: do outro lado do espelho. Florianópolis: UFSC, 2005.

POZZO, R.; VIDAL, L. A cidade contra a Ilha: aspectos da urbanização contemporânea em Florianópolis. Anais XIII Simpósio Nacional de Geografia Urbana. Belo Horizonte, 2011.

RIBEIRO, D. O povo brasileiro. A formação e o sentido do Brasil. São Paulo: Companhia das Letras, 1995.

SANCHÉZ, F. A reinvenção das cidades na virada do século: agentes, estratégias e escalas de ação política. Revista Sociologia Política, n. 16, p. 31-49, jun. 2001.

A reinvenção das cidade para um mercado mundial. Chapecó: Argos, 2003.

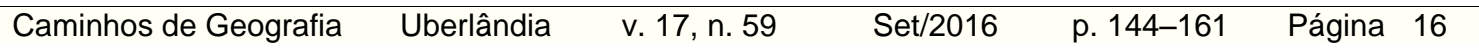


SANTOS, S.S. Uma cidade à venda? Capital imobiliário, poder público e produção do espaço em Florianópolis a partir da década de 1980. Revista de Desenvolvimento Econômico. Ano XIV, n. 26, p. 124-135, 2012.

VAINER, C.B. Pátria, empresa e mercadoria. Notas sobre a estratégia discursiva do Planejamento Estratégico Urbano. In: ARANTES, O. et al. A cidade do pensamento único. Desmanchando consensos. 3.ed. Rio de Janeiro: Vozes, 2000.

VIKTOR, T.A. As transformações urbanos do Rio Vermelho, Florianópolis, e suas repercussões no modo de vida do bairro desde meados de 1960. Revista Santa Catarina em História. v. 4, n. 2, p. 48-63, 2010. 